\title{
Long-term management of children with spina bifida: commentary on the nurses break-out session, June $26^{\text {th }}$ Emma Kelly
}

Address: Dept. of Paediatric Surgery, Royal Belfast Hospital for Sick Children, 180 Falls Road, Belfast, BT12 6BE, UK

Email: Emma Kelly - emma.kelly@belfasttrust.hscni.net

from 53rd Annual Meeting of the Society for Research into Hydrocephalus and Spina Bifida Belfast, UK. 24-27 June 2009

Published: 27 November 2009

Cerebrospinal Fluid Research 2009, 6(Suppl 2):S49 doi:I0.1186/1743-8454-6-S2-S49

This article is available from: http://www.cerebrospinalfluidresearch.com/content/6/S2/S49

(c) 2009 Kelly; licensee BioMed Central Ltd.

The breakout session was aimed to be an informal networking opportunity for nursing staff and other health care professionals, aiming to improve the care of children with spina bifida. The session went very well and the evaluations were very positive. The first session was from Marie McGonnell, our local ASBAH advisor. She gave an outline of her invaluable role as a support for the families especially prenatally.

Following coffee, Mary White gave a talk on catheterisation in schools. This was very interesting and provoked a lot of discussion on how each centre managed their children with neuropathic bladders with regard to catheterisation.

Marie McGrogan (the Coloplast representative for Peristeen), Laura Connolly and Emma Kelly gave a presentation and case discussion on Peristeen rectal irrigation system. This preceded a discussion on the management of neuropathic bowels. To conclude the session, one of the senior Physiotherapists in RBHSC, Finola Beattie gave a presentation on how children with spina bifida are managed their physiotherapy and mobility. Finola had video footage of children in the gym which provided the nursing staff a great insight into the invaluable role of the physiotherapy. All in all, the session was very well received and provided a forum for discussion and learning. 